\title{
O COMPLEXO DE ÉDIPO NAS OBRAS DE KLEIN E WINNICOTT: COMPARAÇÕES
}

Priscila Toscano de Oliveira Marchiolli e Leopoldo Fulgencio

Priscila Toscano de
Oliveira Marchiolli
Psicóloga, mestre
em Psicologia como
profissão e ciência
pela Pontifícia
Universidade
Católica de
Campinas (PUC-
Camp).
Leopoldo Fulgencio
Psicanalista, doutor
em Psicologia
pela Pontifícia
Universidade
Católica de São
Paulo (PUC-
SP), professor
do programa de
Pós-graduação
em Psicologia
da Pontifícia
Universidade
Católica de
Campinas (PUC-
Camp).

RESUMO: Este trabalho objetiva a análise comparativa da noção de complexo de Édipo nas obras de Klein e de Winnicott, como forma de explicitar algumas diferenças e proximidades entre esses autores. Mostrou-se que, enquanto em Klein há a ideia de um Édipo precoce, base para a constituição do ser humano, ligado a fases pré-genitais e à relação do tipo parcial com os objetos, em Winnicott o complexo de Édipo aparece somente numa fase tardia do amadurecimento, quando o indivíduo já está integrado, caracterizando um desenvolvimento saudável.

Palavras-chave: Psicanálise, complexo de Édipo, Winnicott, Klein, sexualidade, amadurecimento emocional.

ABSTRACT: Oedipus complex in Klein and Winnicott's works: Comparisons.This work introduces a comparative analysis of the concept of the Oedipus complex in the works of Klein and Winnicott, as a way to demonstrate some differences and proximities between these authors. It was shown that, while in Klein there is the idea of an early Oedipus complex, the basis for the constitution of human being, related to pre-genital phases and to a partial relationship with objects, in Winnicott the Oedipus complex appears only as a late phase of growth, when the individual is already integrated, featuring a healthy development.

Keywords: Psychoanalysis, Oedipus complex, Winnicott, Klein, sexuality, emotional maturation. 

retende-se demonstrar as principais diferenças entre Klein e Winnicott
quanto às compreensões desses autores com relação ao complexo de Édipo e, sobretudo, com relação ao momento em que o mesmo se estabelece no desenvolvimento emocional e quais são as condições envolvidas nesse processo.

No estudo da história da psicanálise, no que concerne à leitura sobre as relações de continuidades e rupturas entre as propostas desses autores, pode-se reconhecer, ao menos, duas posturas opostas: uma diz respeito ao entendimento de que Winnicott construiu uma obra alicerçada pelos pressupostos kleinianos, mantendo-se dentro do quadro conceitual da autora (AGUAYO, 2002; MEYER, 1994); outra entende haver, em Winnicott, rupturas significativas em relação a Klein (PHILLIPS, 1988; LOPARIC, 1997a, 1997b, 2001, 2006; DIAS, 2003; ROUSSILLON, 2009).

O texto winnicottiano apresenta, por vezes claramente, momentos de concordância e de divergência em relação a Klein (cf. WINNICOTT, 1965va e 1987b) ${ }^{1}$, não só com respeito às formulações sobre o Édipo precoce (WINNICOTT, 1988) mas também a conceitos, como o de inveja inata (WINNICOTT, 1989xf) e posição depressiva (WINNICOTT, 1955c).

Um delineamento mais preciso das rupturas entre os teóricos em questão é tarefa considerada por autores como Aguayo (2002) e Loparic (1997b) um desafio para os pesquisadores da atualidade. Nesse mesmo sentido, entende-se como necessário esse tipo de elucidação porque concepções teóricas divergentes orientam ações clínicas diferentes.

Indubitavelmente, o complexo de Édipo é o conceito central e fundamento da teoria psicanalítica. Sua importância para a psicanálise é de tal ordem que Freud considerou-o o xibolete ${ }^{2}$ (FREUD, 1905/1989, p.214) de sua ciência, ou seja, condição sine qua non para a prática da psicanálise. Tanto Klein como Winnicott tecem afirmações ao longo de suas obras que revelam sua concordância com certos aspectos desta descoberta freudiana. Klein afirma que "a psicanálise provou que o complexo de Édipo é o fator mais importante de todo o desenvolvimento da personalidade" (KLEIN, 1927b/1996, p.200-201); Winnicott, por sua vez, considera que o complexo de Édipo permanece “(...) como um fato central, infinitamente elaborado e modificado, mas irrefutável” (WINNICOTT, 1947a, p.167-168).

\footnotetext{
${ }^{1}$ A obra de Winnicott será apresentada segundo a classificação proposta por Knud Hjulmand (1999). Jan Abram (2008) informou, em artigo recente, que as obras completas de Winnicott seriam publicadas respeitando-se tal classificação.

${ }^{2}$ Xibolete é uma palavra de origem hebraica que significa espiga e, como consta no Velho Testamento, trata-se de uma prova de pertinência a um grupo que resulta numa questão de vida ou morte. Para uma análise sobre os xiboletes da psicanálise para Freud, sugerimos Fulgencio 2008.
} 
No entanto, é possível reconhecer diferenças entre suas concepções sobre o Édipo, tanto em relação a Freud quanto em relação a suas próprias produções: Klein apresenta ao mundo psicanalítico o Édipo precoce (KLEIN, 1928/1996, 1945/1996) vivido em termos de relações parciais de objetos; em Winnicott, encontra-se a recusa do Édipo precoce e uma redescrição stricto sensu do complexo de Édipo vivido quando a criança atinge a maturidade, que a caracteriza como sendo uma pessoa inteira (WINNICOTT, 1988, Parte II).

Segue-se uma análise dos aspectos principais das compreensões desses dois autores sobre o complexo de Édipo, buscando-se explicitar as principais diferenças e proximidades entre eles.

\section{O CONCEITO KLEINIANO DO COMPLEXO DE ÉDIPO}

A compreensão da concepção kleiniana sobre o momento e a maneira como é vivido o complexo de Édipo depende da sua reformulação da teoria da sexualidade, baseada nas posições esquizoparanoide e depressiva.

Esta teoria das posições corresponde, como comentam Greenberg \& Mitchell (1994), a uma reformulação da teoria das fases psicossexuais de Freud, dado que, para ela, na verdade, as fases freudianas se justapõem e se misturam umas às outras. As posições, para Klein, correspondem a modos de funcionamento das relações com os objetos e os mecanismos de defesa a eles associados, sendo que na posição esquizoparanoide “(...) o amor e o ódio, bem como os aspectos bons e maus do seio, são mantidos amplamente separados um do outro" (KLEIN, 1952/1991, p.71-72), e na posição depressiva são unificados, pois “a ansiedade depressiva é intensificada (...) o bebê sente que destruiu ou está destruindo um objeto inteiro com sua voracidade e agressão incontroláveis (...) sente que esses impulsos destrutivos são dirigidos contra uma pessoa amada” (KLEIN, 1952/1991, p.73).

No artigo "O desenvolvimento de uma criança” (1921/1996), Klein faz seu primeiro comentário sobre o complexo de Édipo. Ela apresenta sua leitura, claramente edípica, do caso de Fritz, menino descrito como filho de um casal de sua vizinhança ${ }^{3}$. Afirma esta autora que, uma vez sanadas as dúvidas da criança sobre sexualidade, "o complexo de Édipo começou a ocupar o primeiro plano" (idem, p.57), o que lhe permitiu fazer intervenções como: “a mamãe não pode ser sua mulher porque ela já é mulher do papai, e aí o papai ia ficar sem mulher" (idem, p.56).

Em “Análise de crianças pequenas” (1923/1996) e "Princípios psicológicos da análise de crianças pequenas” (1926/1996), nota-se um início de afastamento

\footnotetext{
${ }^{3}$ Grosskurth (1992) aponta que Fritz, na verdade, é o próprio filho de Klein, Erich.
} 
da descrição clássica do complexo de Édipo, passando a autora a introduzir em seus escritos sua ideia de que ele ocorria muito antes do que Freud postulara. Inicialmente, considerou que o complexo já estaria presente por volta dos 2 ou 3 anos de idade (KLEIN, 1923/1996), deslocando-o depois para o início do segundo ano de vida (KLEIN, 1926/1996).

Argumenta, mais à frente, que o referido complexo já podia ser percebido no desmame, desencadeado pelas frustrações que dele surgiam e pelas que eram geradas no treinamento dos hábitos de higiene (KLEIN, 1926/1996, 1927a/1996, 1927b/1996). Por isso, Klein também propõe modificações ao conceito de superego, porque percebia que crianças muito pequenas já expressavam a existência de um superego muito mais cruel do que o dos adultos, devido à fantasia de “punições como ser castrado, cortado em pedaços, devorado, etc." (KLEIN, 1927a/1996, p.182), derivada da destruição do objeto por suas pulsões sádicoorais e sádico-anais.

Finalmente, em 1928, Klein escreve Estágios iniciais do conflito edipiano, no qual reitera que o início do complexo de Édipo se dá com a frustração gerada no desmame. Esse texto abre passagem para a consideração de que o complexo de Édipo tem seu início ainda em "fases pré-genitais do desenvolvimento" (KLEIN, 1928/1996, p.217), quando o objeto ainda é parcial. A autora afirma, além disso, que o medo da castração e sentimento de culpa relacionados à formação do superego aparecem desde o início do complexo. Essa afirmação a afasta mais uma vez de Freud, embora Klein tenha tentado se mostrar fiel a ele, pois o primeiro considerou tais elementos produtos finais do complexo (FREUD,1931/1989).

A ansiedade inconsciente é um dos pontos mais importantes do pensamento de Klein (SEGAL, 1975). Em 1928, tal conceito começa a ganhar destaque no pensamento da autora ao considerar que, para meninos e meninas, o processo inicial das tendências edípicas provoca grandes quantidades de ansiedade, resultantes das fantasias de ataques contra o corpo da mãe, o que faz emergir uma imago de uma mãe hostil, que “desmembra e castra” (KLEIN, 1928/1996, p.220). No caso do menino, a ansiedade de castração é derivada dessa primeira ansiedade, abrindo espaço para o "complexo de feminilidade” (idem, p.219), relacionado aos desejos frustrados de possuir um órgão especial, gerador da vida, assim como o da mãe.

Esse desejo é, mais tarde, transformado em atitude de agressividade e desprezo em relação à figura feminina e seguido pela fantasia de "superioridade" (idem, p.220), após a descoberta de seu pênis. Quanto à menina, a ansiedade está relacionada ao medo de ter seu interior atacado pela mãe ameaçadora; secundariamente, surge o medo de perder seu amor. A ansiedade, gerada pelo medo da menina de ter sua feminilidade devastada e, do menino, de perder o 
pênis pela ação retaliadora do pai, “colabora para refrear os impulsos edipianos” (idem, p.224).

Claramente, Klein propõe a existência de processos mentais logo no início da vida, que têm como "principal objetivo (...) se apossar do conteúdo do corpo da mãe e (...) destruí-la com todas as armas ao alcance do sadismo” (KLEIN, 1930/1996, p.251). Os ataques são, na verdade, direcionados ao pai e à mãe, já que, em sua fantasia, a vagina da mãe incorpora o pênis do pai, o que a autora nomeia figura dos pais combinados. A ansiedade desencadeada, segundo Klein, "põe em movimento os métodos de defesa mais arcaicos do ego" (idem, p.252), ainda anteriores à capacidade do uso da repressão inconsciente como defesa. Esta tem que lidar com o sadismo do próprio sujeito e com a fantasia de retaliação por parte do objeto. Sendo assim, o ego se defende através do mecanismo da "expulsão" do sadismo e da "destruição" do objeto (ibidem).

O ego da criança, ainda frágil, fica, portanto, submetido a impulsos sádicos e sexuais, os quais se opõem, e sujeito a um superego extremamente cruel (KLEIN, 1928/1996). Nesse momento da obra de Klein, o entendimento é que "uma quantidade extraordinária de ódio" (idem, p.218) advém do fato de o ego ser pouco desenvolvido e ser arrebatado por sentimentos tão fortes, somado à curiosidade sobre a vida sexual, em uma etapa em que a criança ainda não possui domínio do código linguístico; é o ódio a base do conflito edípico.

A ansiedade emergida nessa fase, conforme Klein, é responsável pelo início do mecanismo de identificação, e faz com que a criança “iguale os órgãos” (KLEIN, 1930/1996, p.252) que desejou destruir (pênis, vagina, seio) a outros objetos do mundo que possam lhes ser equivalentes. Obviamente, os novos objetos escolhidos passam a ser suas novas fontes de perigo, uma vez que a ansiedade continua na base dessa relação, compelindo a criança a se deslocar para outros objetos e assim por diante. Essas "novas equiparações” feitas pela criança "formam a base do simbolismo e de seu interesse nos novos objetos" (KLEIN, 1930/1996, p.253).

Para a autora, a saúde, isto é, o contato com a realidade tal como ela é, depende da "capacidade do indivíduo de tolerar a pressão das primeiras situações de ansiedade, já num período muito inicial” (KLEIN, 1930/1996, p.253). No caso de Dick, paciente de 4 anos de idade (descrito como caso de psicose infantil), Klein acredita que o ego da criança, constitucionalmente muito fraco, lançou mão das defesas que inviabilizaram suas experiências de ansiedade. No entanto, acredita que, mesmo mediante tamanha inibição egoica, tenha conseguido criar na análise situações que fizeram com que o menino fosse tomado pela ansiedade, o que permitiu que o trabalho pudesse ser realizado normalmente, tendo a criança retomado seu desenvolvimento (por exemplo, colocou trens em frente 
ao paciente e nomeou um como Papai e o outro como Dick, dizendo que Dick queria entrar na 'estação Mamãe', etc.).

Klein narra que diante desse tipo de paciente ela não pôde esperar para fornecer a interpretação do material inconsciente até que ele tivesse sido comunicado em várias representações, visto que elas eram quase inexistentes: Klein sentiu que suas interpretações precisavam ser desenvolvidas a partir de seu "conhecimento geral” (KLEIN, 1930/1996, p.260). O tratamento deu-se, portanto, a partir dessa via de acesso ao inconsciente e da apresentação, para o sujeito, da relação causadora de ansiedade.

Em 1940, no artigo "O luto e suas relações com os estados maníaco-depressivos”, Klein termina sua exposição sobre a teoria da posição depressiva e passa a relacionar o conflito edípico ao medo da perda do objeto bom. Levando em conta suas reformulações teóricas - sobre o funcionamento mental ser baseado na interação entre amor e ódio, e mais a própria teoria das posições —-, Klein viu necessidade de reapresentar seu conceito de complexo de Édipo em 1945, no artigo “O complexo de Édipo à luz das ansiedades arcaicas”. Nele, passa a relacionar diretamente o complexo à posição depressiva e propõe que o caminho natural da ansiedade, culpa e sentimentos depressivos seja a necessidade de reparação dos objetos. O ódio não é mais encarado como o fator que dispara e fundamenta o conflito edípico. Para Klein, quando a ansiedade persecutória diminui, os sentimentos amorosos podem ocupar o primeiro plano, pois a criança é impelida "por sentimentos de amor e culpa a preservar" (KLEIN, 1945/1996, p.462-463) o pai ou a mãe como figura interna e externa.

Em “Inveja e gratidão” (1957), Klein enfatiza que "todo o desenvolvimento do complexo de Édipo é fortemente influenciado pela intensidade da inveja, a qual determina a força da figura dos pais combinados" (KLEIN, 1957/1991, p.229). A fantasia da mãe contendo o pênis do pai e do pai dentro do corpo da mãe "sempre obtendo gratificação sexual um do outro" (idem) precisa dar lugar à percepção dessas figuras como separadas e ao relacionamento positivo com elas, o que só acontece se a "a inveja do objeto originário” (idem) não tiver sido excessiva. No ano seguinte, em "Sobre o desenvolvimento do funcionamento mental” (1958), Klein declarou-se, por fim, contrária a Freud: "o início do superego antecede de alguns meses o início do complexo de Édipo (...) no segundo trimestre do primeiro ano de vida, junto com o começo da posição depressiva” (KLEIN, 1958/1991, p.273), e é formado pelas “primeiras introjeções do seio bom e do seio mau" (idem). 


\section{CONSIDERAÇÕES DE WINNICOTT SOBRE O COMPLEXO DE ÉDIPO}

Para proporcionar ao leitor uma melhor interpretação acerca das relações teóricas entre os autores em questão, faz-se necessária a retomada da avaliação crítica de Winnicott às propostas de Klein, diferenciando o que ele avalia como contribuições positivas das que considera duvidosas ou que necessitam de revisão.

Como positivas, Winnicott destaca a descoberta das ansiedades primitivas, dos mecanismos de projeção e de introjeção, a proposição do uso da brincadeira como via de acesso ao inconsciente da criança, bem como a descoberta da posição depressiva, considerada por ele a grande contribuição de Klein, porque implica a identificação dos mecanismos referentes ao processo de integração do ego, que engloba "aceitação da responsabilidade por toda a destrutividade que está ligada ao viver" (WINNICOTT, 1965va, p.160).

Embora tenha equiparado o peso desta descoberta kleiniana ao da descoberta freudiana do complexo de Édipo, Winnicott critica a expressão "posição depressiva”, por julgar inapropriado o uso do nome de uma patologia para caracterizar uma etapa do desenvolvimento que considera tão saudável. O autor prefere a designação, não totalmente precisa, de "fase do concernimento" (cf. WINNICOTT 1958b, p.291; 1955c, p.358; 1955d, p.376).

Como aspectos que necessitam de revisão, Winnicott elenca a compreensão kleiniana do sentimento de culpa, assim como a capacidade de se preocupar, que, para ele, devem ser entendidos não como aspectos inatos, mas sim aquisições do processo de desenvolvimento (WINNICOTT, 1965va). Além disso, Winnicott critica o fato de Klein ter considerado "superficialmente" (WINNICOTT, 1965va, p.161) o fator ambiental, o que teria causado em sua argumentação problemas de ordem fundamental, visto que há um período da vida do lactente em que é impossível descrevê-lo sem que se descreva também a mãe, de quem ele "ainda não se tornou capaz de se separar para se tornar um self" (WINNICOTT, 1965va, p.161).

Sobre a teoria da posição esquizoparanoide, Winnicott considera que um ambiente suficientemente bom no início da vida pode transformar seus dois mecanismos básicos — o medo de retaliação e a cisão do objeto em objeto bom e objeto mau - em algo "relativamente sem importância até que a organização do ego torne o bebê capaz de usar mecanismos de introjeção e projeção para obter controle sobre os objetos” (WINNICOTT, 1965va, p.161).

Como "contribuições duvidosas" (1965va, p.162), Winnicott cita a insistência de Klein em manter a teoria das pulsões de vida e de morte, bem como sua compreensão acerca da destrutividade do bebê baseada na hereditariedade e na inveja. Ele também enfatiza sua crítica em relação à tendência da autora de "empurrar a idade em que os mecanismos mentais aparecem cada vez mais 
para trás” (WINNICOTT, 1965va, p.161), confundindo o que é 'profundo' com o que é 'precoce'.

No desenvolvimento da teoria psicanalítica há autores que fazem críticas a Klein similares às de Winnicott. Greenberg \& Mitchell (1994) e comentam três grandes ressalvas às contribuições de Klein: "adesão ao conceito do instinto de morte, a sua pressuposição de extensos conhecimentos e imagens constitucionais e a sua atribuição ao bebê de elaboradas capacidades cognitivas no nascimento, ou pouco antes" (GREENBERG \& MITCHELL, 1994, p.108). Agregando o comentário geral de Greenberg \& Mitchell aos de Winnicott, pode-se afirmar que a grande divergência deste em relação a Klein é a consideração de que ela teria projetado a vivência edípica para um momento em que a criança não tem maturidade para esse tipo de experiência relacional.

Enquanto Klein pressupõe que no início do desenvolvimento o bebê já pode estabelecer relações com objetos (KLEIN, 1952/1991), Winnicott argumenta que ele seria imaturo demais para essa capacidade cognitiva e afetiva (WINNICOTT, 1988). Noutra ocasião, ele comenta a impossibilidade de o bebê sentir inveja, porque tal condição demandaria alto grau de desenvolvimento cognitivo e "sofisticação, isto é, um grau de organização do ego no sujeito que não se acha presente no início da vida” (WINNICOTT, 1959b, p.53), como reconhecer um objeto, suas qualidades, reconhecer o 'eu' com outras qualidades.

No trabalho de Winnicott deve ser, portanto, destacada sua preocupação com modos de relações de objetos mais primitivos do que os que podem ser reconhecidos nos relacionamentos interpessoais, quando o indivíduo já é uma pessoa inteira, que se relaciona com os outros como pessoas inteiras. Assim, já em 1945, Winnicott explicita sua posição de que alguém só vem a se tornar uma pessoa passível de se relacionar com outras pessoas a partir de determinado ponto de seu desenvolvimento e, principalmente, mediante os cuidados do ambiente, realizados de maneira satisfatória (WINNICOTT, 1945d). Para Winnicott, antes de haver a possibilidade do estabelecimento de relações de objeto e, consequentemente, a vivência do complexo de Édipo, uma série de etapas devem ser cumpridas no desenvolvimento emocional, que vão lhe permitindo, gradativamente, a conquista de recursos nessa direção.

Na teoria winnicottiana, o amadurecimento emocional é uma progressão que parte de um estado primeiro de dependência absoluta, momento inicial em que não há uma realidade não-self (WINNICOTT, 1988), que envolve a adaptação suficientemente boa da mãe às necessidades de seu bebê. Esse processo leva a um estado de dependência relativa, ou seja, de amadurecimento no sentido de uma integração que diferencia o Eu do Não-Eu (WINNICOTT, 1969i, 1970b, 1984h) e 
cria condições para a independência quando o indivíduo, na saúde, chega a integrarse como pessoa inteira (WINNICOTT, 1965r). ${ }^{4}$

É somente a partir dessas conquistas que a vida instintual tal como descrita por Freud pode acontecer, e o complexo de Édipo, a fantasia erótica e o desejo pelo objeto podem aparecer. Todo o processo integrativo anterior permite ao indivíduo que integre também seus instintos como elementos advindos de seu próprio eu (WINNICOTT, 1988, 1989vl).

Nessa direção, Winnicott propõe que somente a criança saudável, com desenvolvimento inicial favorável, é capaz de manifestar o sentimento de culpa de forma verdadeira, sem que seja imposta pelo externo, o que seria falso para o self (WINNICOTT, 1955c). O autor também rechaça o estabelecimento de tratamento para a psicose pela via edípica, visto que tal problemática tem origem em fases precoces, fruto de uma provisão ambiental falha ou inexistente (WINNICOTT, 1963c, 1965h, 1989xa).

Todos esses aspectos da teoria winnicottiana são pontos fundamentais para a compreensão da recusa do autor com relação à proposta de Klein do Édipo precoce. Diz Winnicott: "Não posso ver nenhum valor na utilização do termo 'Complexo de Édipo' quando um ou mais de um dos três que formam o triângulo é um objeto parcial” (WINNICOTT, 1988, p.67).

No entanto, percebe-se que as diferenças entre Klein e Winnicott em relação ao complexo de Édipo não se restringem à recusa da noção de Édipo precoce. Trata-se também de uma redescrição winnicottiana do complexo em meninos e meninas e também de sua vinculação apenas à dinâmica neurótica. Salientamse, aqui, quatro aspectos, sem que eles tenham, contudo, a pretensão de esgotar o assunto:

1. Em Winnicott, o complexo de castração no menino traz um elemento novo: a castração não é entendida apenas como angustiante, derivada de uma constante ameaça paterna como sanção aos desejos edípicos, mas é também vista como um alívio ante a imaturidade (sentimento de impotência) da criança para satisfazer, em sua fantasia, o desejo de união erótica com a mãe (WINNICOTT, 1988);

2. O complexo de castração na menina é considerado como fase que será ultrapassada (WINNICOTT, 1986g), o que é diferente de Klein: ainda que esta autora discorde de Freud quanto à importância conferida por ele à descoberta da menina de que não possui um pênis, ela continua a conceber os processos de formação do feminino calcados pela ideia do macho castrado: para ela, a menina se dirige ao pai porque é tomada por ódio e frustração na relação com a mãe, primeiramente pelo desmame, e depois, pela fantasia de que a mãe possui o

\footnotetext{
${ }^{4}$ Para a compreensão da teoria do amadurecimento de Winnicott tomou-se por base o trabalho de sistematização e interpretação da obra deste autor feito por Dias (2003).
} 
pênis do pai (KLEIN, 1928/1996). Para Winnicott, faz mais sentido considerar que a mulher é sempre um trio: o bebê, a mulher-mãe e a mãe da mãe (WINNICOTT, 1986g), e que trava mais batalhas do que o menino, uma vez que se volta contra sua própria fonte de vida.

3. A gênese da psicose é afastada do complexo de Édipo e é relacionada a falhas ambientais em etapas primitivas do desenvolvimento, quando não há ainda uma pessoa integrada (WINNICOTT, 1955d, 1968a); a ação clínica para estes casos se afasta da interpretação do material edípico. Winnicott considera que, para as dinâmicas de personalidade não neuróticas, o trabalho tradicional não atinge resultado positivo, mas "fenômenos da vida cotidiana” (WINNICOTT, 1955d, p.466), como uma amizade ou um período de cuidado durante uma doença física, têm para elas um "poder curativo" (idem).

4. Considera-se a existência real dos pais, e não somente suas imagos introjetadas pela criança, no que diz respeito à importância do ambiente durante a vivência do Édipo. Nessa etapa, o ambiente não tem mais a função de estruturação da personalidade, mas pode, através de sua estabilidade, possibilitar à criança uma passagem tranquila pelo Édipo, sem construções excessivas de defesas (WINNICOTT, 1989xi, 1986g, 1989xa).

Pode-se dizer, portanto, que Winnicott deu novo valor e novo lugar ao complexo de Édipo: se por um lado ele destituiu a importância que lhe dera Klein, por outro tornou mais precisa sua dinâmica.

\section{CONCLUSÕES}

A trama básica do complexo de Édipo, esboçada pelos autores, não diz respeito às mesmas dinâmicas psicoafetivas. A maior discordância entre os teóricos em foco certamente é a questão do momento em que se estabelece o complexo de Édipo e as condições envolvidas no processo: para Klein, ele se inicia na vida do bebê em fase pré-genital e este bebê é maduro emocionalmente, capaz de se relacionar com os objetos e de fantasiar sobre eles (KLEIN, 1928/1996, 1945/1996); para Winnicott, a vivência do Édipo em termos de objetos parciais é impraticável: o bebê não é uma pessoa total e não pode se integrar sem o desenvolvimento anterior saudável. Este lhe possibilitará, depois, a integração dos instintos, as condições para discriminar objetos e vivenciar o Édipo (WINNICOTT, 1965vc, 1970b). Para Winnicott, a separação entre "eu” e "não-eu” e a possibilidade de “sentir que a vida é real” ou "digna de ser vivida” (WINNICOTT, 1967b, p.137) são conquistas do desenvolvimento saudável.

Além disso, nota-se também que aspectos inerentes à dinâmica edípica são compreendidos de forma diferente por Klein e por Winnicott. É o caso da fantasia de castração masculina, vista por Klein como aterrorizante (KLEIN, 1928/1996) 
e, por Winnicott, como um alívio para o sentimento de impotência (WINNICOTT, 1988). A formação da identidade feminina também é divergente, pois em Klein, a fantasia do macho castrado é base do psiquismo feminino e em Winnicott há o reconhecimento de outros aspectos como fundamentais para os processos psíquicos da mulher.

Com relação às diferentes dinâmicas de personalidade e sua ligação com o complexo de Édipo, também se notam divergências bem precisas. Klein entende a psicose como um problema que também tem sua gênese na ansiedade gerada com as tendências edípicas (KLEIN, 1930/1996). Mas Winnicott assevera que o complexo de Édipo não se relaciona de maneira alguma com a dinâmica psicótica, uma vez que esta se origina em fases mais primitivas do desenvolvimento (WINNICOTT, 1963c).

A clínica winnicottiana dos estados não neuróticos, sejam eles psicóticos, depressivos, antissociais, etc., pressupõe encaminhamentos que se afastam do setting tradicional, pois a conduta do analista está ligada muito mais ao "manejo" (WINNICOTT, 1955d, p.460), ou seja, ao oferecimento de condições (holding, handling) que permitam ao paciente o descongelamento das "situações de fracasso ambiental" (WINNICOTT, 1955d, p.466).

No que concerne à neurose, ainda que o tratamento transcorra sobre as bases da análise e interpretação ${ }^{5}$ do material edípico, observam-se em Winnicott elementos novos, como as compreensões sobre a castração masculina, sobre os processos identificatórios femininos e a consideração da figura real dos pais e de seu modo de se relacionar com a criança também durante o conflito edípico. Esses elementos podem apontar (transferido o cenário para a situação analítica) para uma postura do analista que envolva o oferecimento ao paciente de uma situação de confiabilidade e previsibilidade, em que este possa ser tolerado em suas deslealdades e ataques provenientes da dinâmica edípica. Tal tolerância poderia implicar, ainda, momentos nos quais a interpretação de tais ataques não seria o elemento mais importante. O próprio Winnicott considera que, em muitas situações, é mais proveitoso “esperar” (WINNICOTT, 1969i, p.121) pela evolução natural da confiança do paciente em relação ao analista do que preocupar-se com a "produção de interpretações" (idem). Embora ele não estivesse se referindo especificamente à dinâmica neurótica, acreditamos que sua descrição do complexo de Édipo também possa abarcar, de certa forma, esses aspectos clínicos.

\footnotetext{
${ }^{5} \mathrm{O}$ tema da interpretação na obra de Winnicott também pode ser desenvolvido em termos de aproximações e afastamentos em relação à teoria clássica. Para uma apreciação das colocações de Winnicott sobre a interpretação na psicanálise, indicamos Winnicott (1989o) e Sipahi (2006).
} 
O caminho percorrido até aqui possibilita explicitar a divergência radical entre os autores quanto ao tema. Enquanto Klein tentou nitidamente aproveitar o material freudiano para explicar até mesmo os fenômenos da pré-genitalidade, Winnicott considerou que a chegada ao complexo de Édipo corresponde a um grande ganho em termos de saúde (ausência de psicose), mediante cuidados ambientais prévios satisfatórios.

A comparação teórica entre os autores leva esta pesquisa, invariavelmente, à comparação entre as clínicas de Winnicott e de Klein, tratando-se de uma tarefa árdua e vasta e que ultrapassa os objetivos aqui pretendidos. O intuito da argumentação foi tão somente o apontamento de novos direcionamentos de pesquisa que possam servir de orientação para ações efetivas junto aos que necessitam de ajuda profissional.

Recebido em 8/1/2010. Aprovado em 19/12/2010.

\section{REFERÊNCIĀS}

ABRAM, J. (2008) Education Section — Donald Woods Winnicott (18961971): A brief Introduction. The International Journal of Psychoanalysis, n.6, v.89. Londres: Institute of Psychoanalysis, p.1.189-1.217.

AGUAYO, J. (2002) Reassessing the clinical afinity between Melanie Klein and D. W. Winnicott (1935-51): Klein's unpublished 'notes on baby' in historical context. The International Journal of Psychoanalysis, v.83, n.5, Londres: Institute of Psychoanalysis, p.1.133-1.152.

DIAS, E.O. (2003) A teoria do amadurecimento de D.W. Winnicott. Rio de Janeiro: Imago.

FREUD, S. (1989) Edição standard brasileira das obras psicológicas completas de Sigmund Freud. Rio de Janeiro: Imago.

(1905) “Três ensaios sobre a teoria da sexualidade”, v.VII, p.118-217.

(1931) “Sexualidade Feminina”, v.XXI, p.257-279.

FULGENCIO, L. (2008) O método especulativo em Freud. São Paulo: Educ.

GREENBERG, J.R. \& MITCHELL, S.A. (1994) Relações objetais na teoria psicanalítica. Porto Alegre: Artes Médicas.

GROSSKURTH, P.(1992) O mundo e a obra de Melanie Klein. Rio de Janeiro: Imago.

HJULMAND, K. (1999) Lista completa das publicações de D.W. Winnicott. Revista de Filosofia e Psicanálise Natureza Humana, v.1, n.2, São Paulo: DWW Editorial, p.459-517.

KLEIN, M. (1996) Amor, culpa e reparação e outros trabalhos (1921-1945). Volume I das obras completas de Melanie Klein. Rio de Janeiro: Imago. (1921) "O desenvolvimento de uma criança”, p.21-75. 
(1923) “Análise de crianças pequenas”, p.100-128.

(1926) "Princípios psicológicos da análise de crianças pequenas", p.152-163.

(1927a) “Simpósio sobre análise de crianças”, p.164-196.

(1927b) "Tendências criminosas em crianças normais", p.197-213.

(1928) "Estágios iniciais do conflito edipiano”, p.214-227.

(1930) "A importância da formação de símbolos no desenvolvimento do ego”, p.249-264.

(1940) "O luto e suas relações com os estados maníaco-depressivos", p.385-412.

(1945) “O complexo de Édipo à luz das ansiedades arcaicas", p.413464.

(1991) Inveja e gratidão e outros trabalhos (1946-1963). Volume III das obras completas de Melanie Klein. Rio de Janeiro: Imago.

(1952) “As origens da transferência”, p.70-79.

(1957) “Inveja e gratidão”, p.205-267.

(1958) “Sobre o desenvolvimento do funcionamento mental”, p.268279.

LOPARIC, Z. (1997a) Winnicott: uma psicanálise não edipiana. Revista de Psicanálise da Sociedade Psicanalítica de Porto Alegre, v.4, n.2, Porto Alegre: SPPA, p.375-387.

. (1997b) "Winnicott e Melanie Klein: conflito de paradigmas", in CATAFESTA, I.F.M (Org.). A clínica e a pesquisa no final do século: Winnicott e a Universidade. São Paulo: Lemos.

. (2001) Esboço do paradigma winnicottiano. Cadernos de História e Filosofia da Ciência, v.11, n.2, Campinas: CLE, p.7-58.

. (2006) De Freud a Winnicott: aspectos de uma mudança paradigmática. Revista de Filosofia e Psicanálise Natureza Humana. v.8, n. especial 1, São Paulo: DWW editorial, p.21-47.

MEYER, L. (1994) O que faz fracassar uma formação? Percurso, v.12, São Paulo: Departamento de Psicanálise do Instituto Sedes Sapientiae, p.83-88.

PHILIPS, A. (1988) Winnicott. São Paulo: Ideias e Letras.

ROUSSILLON, R. (2009) Transitionnel et réflexivité. Les Lettres de La Société de Psychanalyse Freudiene, n.21, Paris: Societé de Psychanalyse Freudiene, p.123-140.

SEGAL, H. (1975) Introdução à obra de Melanie Klein. Rio de Janeiro: Imago.

SIPAHI, F.M. (2006) “A interpretação na psicanálise”, Dissertação de mestrado, Programa de Pós-graduação stricto-sensu em Psicologia clínica, Pontifícia Universidade Católica de São Paulo.

WINNICOTT, D.W. ${ }^{6}$ (1978/1945d) "O desenvolvimento emocional primitivo”, in Da Pediatria à Psicanálise. Rio de Janeiro: Francisco Alves. (1947a/2008) “A criança e o sexo", in A criança e seu mundo. Rio de Janeiro: LTC. . (1978) Da pediatria à psicanálise . Rio de Janeiro: Francisco Alves.

\footnotetext{
${ }^{6}$ A obra de Winnicott é apresentada segundo classificação proposta por Knud Hjulmand, publicada no v.1, n.2, da revista de filosofia e psicanálise Natureza Humana, 1999, p.459-517.
} 
(1955c) "A posição depressiva no desenvolvimento emocional normal”, p.437-458.

(1955d) “Aspectos clínicos e metapsicológicos da regressão no contexto psicanalítico”, p.459-482.

(1958b) "A agressividade e sua relação com o desenvolvimento emocional”, p.355-374.

(1959b/1994) "Resenha de Envy and Gratitude", in Explorações Psicanalíticas. Porto Alegre: Artes Médicas.

. (1982) O ambiente e os processos de maturação. Porto Alegre: Artes Médicas

(1963c) “Os doentes mentais na prática clínica”, p.196-206.

(1965h) "Classificação: existe uma contribuição psicanalítica à classificação psiquiátrica?”, p.114-127.

(1965r) "Da dependência à independência no desenvolvimento do indivíduo”, p.79-87.

(1965va) "Enfoque pessoal da contribuição kleiniana”, p.156-162.

(1965vc) "Provisão para a criança na saúde e na crise”, p.62-69.

(1975) O brincar \& a realidade. Rio de Janeiro: Imago.

(1967b) “A localização da experiência cultural”, p.133-144.

(1969i) "O uso de um objeto e relacionamento através de identificações”, p.121-132.

(1968a/1997) "A etiologia da esquizofrenia infantil em termos do fracasso adaptativo”, in Pensando sobre crianças. Porto Alegre: Artes Médicas.

(1994) Explorações psicanalíticas. Porto Alegre: Artes Médicas.

(1970b) “A experiencia mãe-bebê de mutualidade”, p.195-202.

(1984h) “Sum: eu sou”, p.41-52.

(1986g) “Este feminismo”, p.183-196.

(1987b/1990) O gesto espontâneo. São Paulo: Martins Fontes.

(1988/1990) Natureza humana. Rio de Janeiro: Imago.

(1989o) “A interpretação na psicanálise”, p.163-166.

(1989vl) "Psiconeurose na infância”, p.53-58.

(1989xa) "O uso do objeto no contexto de Moisés e o monoteísmo", p.187-191.

(1989xi) “Comentários sobre 'On the Concept of the superego', de Joseph Sandler”, p.353-358.

(1989xf) "Primórdios de uma formulação de uma apreciação e crítica do enunciado kleiniano da inveja”, p.340-347.

(1989) Tudo começa em casa. São Paulo: Martins Fontes.

Priscila Toscano de Oliveira Marchiolli

priscila_toscano@yahoo.com.br

Leopoldo Fulgencio

leopoldo.fulgencio@gmail.com 